\title{
Reactive Power and Voltage Control in Deregulated Environment
}

\author{
Dapu Zhao, Yixin Ni, Senior Member, IEEE, Jin Zhong, Shousun Chen
}

\begin{abstract}
Reactive power support and Voltage control is a key type of ancillary services in the deregulated electrical power market. A review of some important issues of reactive power support, including cost analysis, reactive power pricing, valuation, is presented in this paper. An Optimal Power Flow (OPF) is used based on real time pricing theory. Two object functions are modeled respectively: minimization of network loss and minimization of total cost to supply reactive power. A real-valued Genetic Algorithm (GA) is also used to help searching the global optimum and verify the solutions. An IEEE 30-bus system is used for the studies.
\end{abstract}

Index Terms - reactive power and voltage control, ancillary services, optimal power flow, genetic algorithm, reactive power costs

\section{INTRODUCTION}

$\mathrm{E}$ lectric power systems all over the world are moving toward deregulated electricity markets. In power system operation, ancillary services are needed to ensure the generation and transmission. Reactive power and voltage control is one of the ancillary services used to maintain the voltage profile through injecting or absorbing reactive power. Reactive power services play an important role as follows:

- Satisfy the requirement of reactive power load.

- Control bus voltage in a system wide.

- Decrease the network loss.

- Relieve the transmission block.

- Provide sufficient reserve to ensure the security of system in emergency.

In integrated power systems, reactive power is provided and consumed in a simple manner. Power factor penalties have been used to pricing reactive power for decades. Reactive power support is regarded as the obligation of generators or grid owners. The system operators use a reactive power optimization program in which real power loss is considered. In this situation, the reactive power suppliers and consumers cannot make their own decision on how to use reactive power efficiently.

Reactive power support may be provided by a variety of devices, including generators, synchronous condensers, shunt capacitors/reactors and static VAr compensators (SVCs). In the deregulated environment, these devices

Dapu Zhao is with the Department of Electrical engineering, Tsinghua University, Beijing 100084, China and the Graduate School at Shenzhen, Tsinghua University, Shenzhen 518055, China. (e-mail: zdp00@mails.tsinghua.edu.cn).

Yixin Ni and Jin Zhong are with the University of Hong Kong, Hong Kong, China.(e-mail: yxni@eee.hku.hk,jzhong@eee.hku.hk)

Shousun Chen is with the Department of Electrical engineering, Tsinghua University, Beijing 100084, China. (e-mail: luochen@163bj.com) belong to different entities that have their own costs and benefits. There should be means to evaluate the reactive power resources and pricing it appropriately. The costs of the suppliers should be considered. A framework needs to be established to procure the service and remunerate the suppliers. The following part of this paper will focus on economic analysis of reactive power service.

Because a large percent of the reactive power requirement of loads are satisfied by the capacitors in current world, the role of capacitors and the effect of capacitors' location are also discussed. At last, the possibility of establishing a reactive power market will be discussed.

\section{REACTIVE POWER ISSUES}

\section{A. Cost of reactive power}

Although reactive power costs constitute only about $1 \%$ of total power industry costs [1], it's still important to make it clearly analyzed when the reactive power market is concerned. In economics, the total cost of commodities consists of a fixed cost component and a variable cost component.

Fixed cost is mainly the capital investment of equipments. Generators, although their main purpose is producing real power, they play an important role in many other ancillary services. Some markets roughly think that the investment cost is all real power cost. Several research works propose to allocate this cost to different function [2]. One simple way is to divide it according to the power factor. Since the reactive power produced by generators is equivalent to that of synchronous condensers, the cost of condensers can be used as a proxy to estimate the cost of generators [3].

Variable costs in economics are those costs connected to the output quantity. Without any fuel cost to generate reactive power, the variable cost of generators include maintenance and operation cost and opportunity cost.

Opportunity cost is considered as the most important part of reactive power cost. The capacity of generators is limited by the synchronous generator armature current limit, the field current limit, and the under-excitation limits. Because of these limits, the production of reactive power may require a reduction of real power output. Opportunity cost is the lost benefit of this reduction of real power output of the generator. A method to calculate opportunity cost is provided in [2].

Other equipments like synchronous condensers, shunt capacitors, STATCOMs, and SVCs don't produce real power, so they don't have opportunity cost.

\section{$B$. Value of reactive power}

The value of reactive power support is related to their 
contributions to system security and stability. The value measure the effect to control system voltage profile, reduce network loss and the power block. A reasonable valuation method can encourage and conduct investigation of reactive power equipment.

The value of reactive power are not depend on the cost, but related to several factors. Reactive power is location dependent, and long distance transfer is not wanted. A reactive power source near the load center can satisfy the requirement more efficiently, so it has a higher value. The resources which can provide reactive power dynamically can respond a reactive power requirement immediately take more advantages to maintain the stability of the system. Thus the dynamic resources such as synchronous condensers are more valuable than shunt capacitors.

The concept of "value curves" is introduced to quantify the relative importance of dynamic reactive power sources in [4]. An equivalent reactive compensation (ERC) method was proposed to determine the value curves. Another method using a sensitivity analysis is also proposed.

\section{Pricing of reactive power support}

In vertically integrated power industries, the cost of reactive power support is normally recovered by including the cost in the real power price or using load power factor penalty. These methods ignore the value contribution of reactive power for the system control.

Pricing of reactive power support has been an important issue. An accurate pricing structure of reactive power is not only profitable to recover the costs of reactive power providers, but also provide useful economic information for real-time operations.

There are two kinds of pricing mechanisms in electricity markets: the spot price based on the marginal cost of system production, which realized a social welfare maximum, and the cost allocation method, which aim at cost recovery.

1) Real time pricing

The spot price theory was proposed by F. C. Schweppe [5]. The spot price for electric energy buying and selling is determined by the supply and demand conditions at that instant. The theory is extended to reactive power in [6] and a real-time pricing structure of reactive power is established. Capital costs are included in reactive power price in [3], and opportunity cost are considered as the reactive power production cost of generators in [2].

Real-time pricing approach can provide economic information for system operation. However, it has several disadvantages in practical applications. In some cases, the real-time price is quite sensitive to the system constraints and operation conditions, which could lead to considerable price fluctuations. The real-time price is usually obtained from OPF based algorithms, which have convergence problems because of numerous nonlinear constraints. The revenue gained by the real-time price may not be sufficient to recover the total cost. Furthermore, it doesn't consider the higher value of dynamic resources.

Several modified OPF approaches are proposed to solve above problems. A decoupled optimal power flow formulation is used to carry out active and reactive power pricing simultaneously and independently [7]. In their formulation, the problem is divided into two sub-problems. The real power sub-problem optimizes the cost of generation, and the reactive sub-problem optimizes the network loss. Another decoupled method is proposed in [8]. The active power sub-problem minimizes total operating costs of providing active power, while the reactive power sub-problem minimizes the total operating costs of providing reactive power plus a specified amount of active power at the balance generator.

\section{2) Cost allocation}

The principle of cost allocation methods is allocating the total cost of reactive power supply to each load. Traditional allocation method can also used in a reactive power cost allocation, such as postage stamp, contract path, and MW mile method. However, these methods are too rough and are not suitable in electrical market.

Several new style methods are proposed. A power flow tracing based cost allocation method for reactive power service has been suggested in [9]. The method provides useful information for reactive power planning and recover the reactive power production and transmission cost properly.

\section{Consideration of voltage control}

Voltage control is an important aspect of reactive power service. However, it isn't considered in most pricing structures because of the difficulty to determine which part of reactive power is used for voltage control. In [10], reactive power support of generators is defined into two functions: reactive power delivery and voltage control. Reactive power delivery satisfies reactive demands of loads, and voltage control enforces the voltage profile of the system under normal and emergence conditions. Both parts are charge independently. In [11], the reactive power services an decomposed into two types: one is voltage profile management and reactive dispatch; the other is voltage control. Accordingly, the price is also decouple d into a part related to the system losses cost and apart related to the security margins enhancement.

\section{E. Establishment of reactive power market}

To establish a competitive reactive power market is the most effective way to promote the social benefits. By making costs and price more transparent, it may encourage greater efficiencies in the provision and consumption of reactive power. The question of unbundling reactive power service is about how reactive power supplies should be organized and priced, and how reactive power costs should be recovered from consumers.

A reactive power procurement structure is proposed in [12]. A social advantage function is maximized for the ISO to determine how to procure reactive power service form the suppliers. The design of a competitive market for reactive power services is presented in [13]. A compromise function is used to consider several contradictory objectives such as total payment, system loss and transaction curtailment. The same authors designed a localized competitive market based on localized voltage control areas [14].

\section{MODEL AND ALGORITHMS}

\section{A. OPF model}

In this paper we assume the active and reactive power demands are known and kept constant during OPF solution. 
Two objective functions are used.

1) Objective 1

Minimize: Total Cost of Real Power Generation

$$
C_{G p}=\sum_{i \in N G} C_{G p i}\left(P_{G i}\right)
$$

2) Objective 2

Minimize: System transmission losses

$$
P_{\text {Loss }}=0.5 \sum_{i, j}\left(G_{i j} \cdot\left(V_{i}^{2}+V_{j}^{2}-2 V_{i} V_{j} \cos \left(\theta_{i}-\theta_{j}\right)\right)\right)
$$

\section{3) Constraints}

The optimization of above objectives is subject to a number of constraints. The equality constraints are load flow equations:

$$
\begin{gathered}
P_{G i}-P_{D i}-P(V, \theta)=0 \\
Q_{G i}-Q_{D i}-Q(V, \theta)=0
\end{gathered}
$$

The inequality constraints are

Generation limits:

$$
\begin{gathered}
P_{G i}^{M i n} \leq P_{G i} \leq P_{G i}^{M a x} \\
Q_{G i}^{M i n} \leq Q_{G i} \leq Q_{G i}^{M a x}
\end{gathered}
$$

Voltage limits:

Transmission limits:

$$
V_{i}^{M i n} \leq V_{i} \leq V_{i}^{M a x}
$$

$$
S_{i j} \leq S_{i j}^{\operatorname{Max}}
$$

Reactive power output limit of capacitors:

Where

$$
Q_{c i}^{M i n} \leq Q_{c i} \leq Q_{c i}^{\operatorname{Max}}
$$

$P_{G i}$

$P_{G i}^{M i n}, P_{G i}^{M a x}$

$Q_{G i}$

$Q_{G i}^{M i n}, Q_{G i}^{M a x}$

$P_{D i}$

$V_{i}$

$\theta_{i}$

$V_{i}^{\operatorname{Max}}, V_{i}^{\operatorname{Min}}$

$S_{i j}$

$S_{i j}^{M a x}$

$Q_{C i}$

$Q_{C i}^{\operatorname{Min}}, Q_{C i}^{\operatorname{Max}}$

$G_{i j}$

$P_{\text {Loss }}$

$N G$

$N C$

$C_{G p i}\left(P_{G i}\right)$

$C_{G q i}\left(Q_{G i}\right)$

$C_{C q i}\left(Q_{C i}\right)$
Active power output at bus i;

Active power limits of the unit at bus i;

Reactive power output at bus i;

Reactive power out put at bus i;

Active power load at bus i;

Voltage phase angle at bus $i$;

Voltage magnitude at bus i;

Voltage magnitude limits;

Transmission line load of line $\mathrm{i}-\mathrm{j}$;

Transmission line limits;

Reactive power output of capacitor at bus $i$;

Reactive power output limits;

the Conductance of line $i-j$

The totol transmission loss of real power;

The set of all generators;

The set of all capacitors;

Real power cost of the unit at bus $i$;

Reactive power cost of the unit at bus i;

Reactive power cost of capacitor at bus $i$;

\section{B. Genetic algorithms}

Many nonlinear programming approaches are used to solve OPF problems. Although these techniques have been successfully implemented in existing power systems, difficulties remain. One problem is that it is easy to be caught by a local optimum solution. Since OPF is not a mathematically convex problem, most techniques might converge to a local optimum instead of a unique global optimum. If the starting point is located near the global optimal point, the solution obtained may be true. However, there is no guarantee of this. The other problem is it's difficult to converge because of its non-linear constraints.

Genetic algorithm (GA) is a stochastic search algorithm modeled on the genetic processes occurring in nature. GA starts with a population of randomly generated candidates and evolves towards better solutions by applying genetic operators (selection, crossover, mutation, etc.). This algorithm can search for a global solution using multiple path and treat integer problem naturally.

\section{1) Control variables}

The control variables are the real and reactive power output of generators, except for the swing bus. The reactive power output of shunt capacitors Qc.

A real-valued method was used, so the encode and decode step are simple and give more information of this specific problem. And it has better performance to solve the high precise problems than the binary GA.

\section{2) Fitness function}

Fitness function is used to evaluate the individuals. The constraints need to be considered as penalty in the fitness function. These constrains include the boundary of Voltage on all the buses, and power output limit of the swing bus generator. Other nonlinear constraints like transmission limits are also added as penalty terms to the objective function. For the convenience of genetic operation, we make it negative. Thus the minimization of objective is equivalent to maximization of the fitness function as follows.

$$
\begin{aligned}
F_{\text {fitness }} & =-P_{\text {Loss }} \\
& -M_{1} \sum_{i=1}^{N}\left(\left[\max \left\{0, V_{i}-V_{i}^{M a x}\right\}\right]^{2}+\left[\max \left\{0, V_{i}^{M i n}-V_{i}\right\}\right]^{2}\right) \\
& -M_{2} \sum_{l}\left[\max \left\{0, S_{l}-S_{l}^{M a x}\right\}\right]^{2}
\end{aligned}
$$

Where $M_{1}, M_{2}$ are large numerial values, called the penalty factors. When constraints are violated, the fitness function is remarkable smaller than normal. Then the individual has less chance to evolve to the next generation.

3) Genetic operation

A normalized ranking selection technique is preferable in this problem, because the selected results are only determined by the order of the fitness value, rather than the numerical value in "roulette rule" method. Thus it's simple to formulate the fitness function, without considering the sign of the fitness value or adjust it.

Multiple crossover and mutation operators are used to get better performance. Theses operators include uniform mutation, non-uniform mutation, boundary mutation, simple crossover, arithmetic crossover and heuristic crossover.

\section{4) Algorithm Details}

The process of the algorithm is detailed as follows.

- $\quad$ Step 1: Determine the boundary of control variables. Choose a desired population size and initialize the starting population.

- Step 2: For each individual in current population, carry out a power flow calculation. Evaluate individuals according to the objective function and fitness function.

- Step 3: Use genetic operators to generate a new population of individuals. 
- $\quad$ Step 4: If convergence criteria met, stop; else go to step 2.

The iteration will stop when the best individuals of several populations don't change any more or reach the maximum number of populations.

\section{CASE STUDY AND RESULTS}

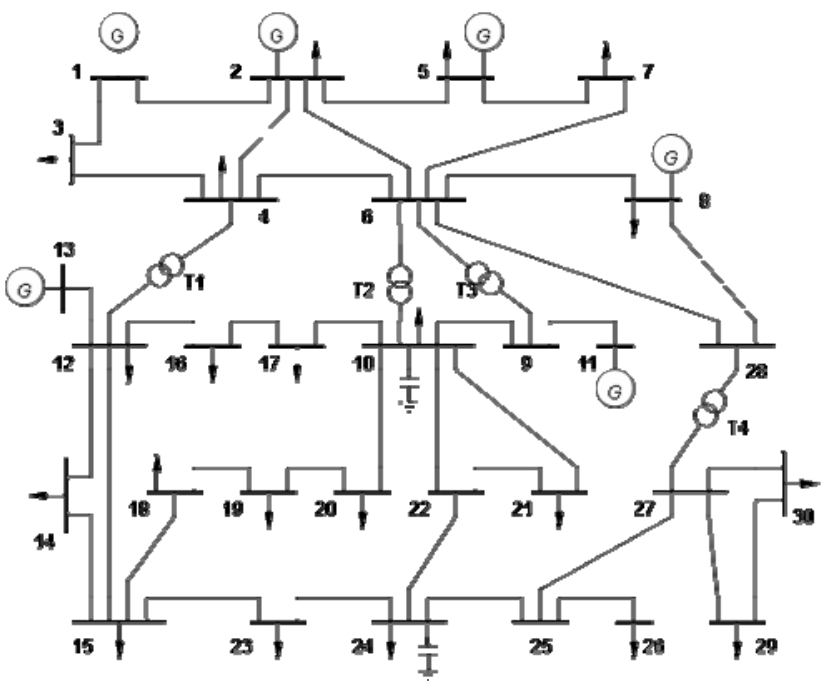

Fig. 1. IEEE 30-bus power system

The IEEE 30-bus power system is used in this work, which is shown in Fig. 1. The network consists of 48 branches, six generator-buses and 20 load-buses. The possible reactive power source installation buses are 10 and 24. $P V$-buses are bus $2,5,8,11,13$, and $V \theta$ bus is bus 1 . The others are $P Q$-buses.

TABLE I

CASE STUDY RESUlTS OF GA

\begin{tabular}{|c|c|c|}
\hline & Case 1 & Case 2 \\
\hline $\begin{array}{l}\text { Objective } \\
\text { function }\end{array}$ & $P_{\text {Loss }}$ & $C_{G p}=\sum_{i \in N G} C_{G p i}\left(P_{G i}\right)$ \\
\hline $\begin{array}{c}P_{G} \\
\text { (Real Power } \\
\text { output of } \\
\text { generator } \\
\text { buses) }\end{array}$ & $\begin{array}{l}35.42 \\
75.90 \\
40.00 \\
50.00 \\
55.00 \\
30.00 \\
\end{array}$ & $\begin{array}{l}63.38 \\
80.00 \\
30.61 \\
50.00 \\
33.50 \\
30.00 \\
\end{array}$ \\
\hline $\begin{array}{c}Q_{G} \\
\text { (Reactive } \\
\text { Power } \\
\text { output of } \\
\text { generator } \\
\text { buses) }\end{array}$ & $\begin{array}{c}8.28 \\
5.16 \\
26.92 \\
49.27 \\
6.53 \\
0.06\end{array}$ & $\begin{array}{c}5.29 \\
16.83 \\
24.02 \\
50.00 \\
-4.01 \\
3.44\end{array}$ \\
\hline$Q_{C}$ & $\begin{array}{c}4.38 \\
10.00\end{array}$ & $\begin{array}{l}8.03 \\
7.62\end{array}$ \\
\hline$P_{G \Sigma}$ & 286.32 & 287.49 \\
\hline$Q_{G \Sigma}$ & 96.22 & 95.97 \\
\hline$P_{\text {Loss }}$ & 2.924 & 4.089 \\
\hline$Q_{\text {Loss }}$ & 20.41 & 20.68 \\
\hline
\end{tabular}

\section{A. Comparison of different objective}

The results of two objective functions computed by GA method are listed in Table 1.

Although the results are close, it can be infer that when the costs of generation is minimized, the loss on the transmission network are not minimized.

\section{B. Comparison of $O P F$ and $G A$}

Choose the objective of minimizing the real power loss, and solve the problem both by OPF and GA. The results are listed in Table 2.

TABLE 2

RESULTS OF OPF AND GA

\begin{tabular}{|c|c|c|}
\hline & $\mathrm{OPF}$ & GA \\
\hline $\begin{array}{l}\text { Objective } \\
\text { function }\end{array}$ & \multicolumn{2}{|c|}{$P_{\text {Loss }}$} \\
\hline $\begin{array}{c}P_{G} \\
\text { (Real Power } \\
\text { output of } \\
\text { generator } \\
\text { buses) }\end{array}$ & $\begin{array}{l}31.48 \\
80.00 \\
40.00 \\
50.00 \\
55.00 \\
30.00\end{array}$ & $\begin{array}{l}35.42 \\
75.90 \\
40.00 \\
50.00 \\
55.00 \\
30.00\end{array}$ \\
\hline $\begin{array}{c}Q_{G} \\
\text { (Reactive } \\
\text { Power output } \\
\text { of generator } \\
\text { buses) }\end{array}$ & $\begin{array}{c}-0.33 \\
20.99 \\
27.50 \\
50.00 \\
9.92 \\
3.51 \\
\end{array}$ & $\begin{array}{c}8.28 \\
5.16 \\
26.92 \\
49.27 \\
6.53 \\
0.06 \\
\end{array}$ \\
\hline$Q_{C}$ & $\begin{array}{l}8.96 \\
1.88\end{array}$ & $\begin{array}{c}4.38 \\
10.00\end{array}$ \\
\hline$P_{G \Sigma}$ & 286.48 & 286.32 \\
\hline$Q_{G \Sigma}$ & 111.59 & 96.22 \\
\hline$P_{\text {Loss }}$ & 3.083 & 2.924 \\
\hline$Q_{\text {Loss }}$ & 21.51 & 20.41 \\
\hline $\begin{array}{c}\text { Time } \\
\text { consuming }\end{array}$ & 3 & 35 \\
\hline
\end{tabular}

It can be seen that OPF has a higher performance than GA. But GA can find a better solution than OPF. It's prove the solution of the OPF is not the global optimum.

\section{Discussion of $G A$}

In above GA model, we use the reactive power output of generators instead of voltage of PV buses as the control variables to make the concept of "reactive power support" clearly. Thus, when proceed the power flow calculation, the PV buses are considered as PQ buses. However, using voltage of PV buses as control variables can get the same solution.

The algorithm can always converge to a global solution. Sometimes it is needed to calculate multiple times to compare and get the stable and most optimized solution.

The performance of the algorithm is highly dependent to the fitness function evaluation which is, in this context, a power flow calculation for each individual of all the populations.

\section{CONCLUSION}

This paper makes a comprehensive survey of the important issues about reactive power in deregulated environment. Establish a reactive power market is not only possible but also profitable.

As a new area of research, this paper is not detailed enough. The model we used is quite simple. Improvement of the OPF and GA programs will be made to get more useful result. More objective will be modeled in further work. 


\section{REFERENCES}

[1] B. Kirby and E. Hirst, "Ancillary Service Details: Voltage Control". Oak Ridge National Laboratory, Oak Ridge, Tennessee, Nov. 1997.

[2] J. W. Lamont and J. Fu, "Cost analysis of reactive power support", IEEE Transactions on Power Systems, Vol. 14, No. 3, pp. 890-898, 1999.

[3] S. H. Hao and A. Papalexopoulos, "Reactive Power Pricing and Management", IEEE Transactions on Power Systems, Vol. 12, No. 1, pp. 95-104, 1997.

[4] W. Xu, Y. Zhang, L. C. da Silva, P. Kundur, and A. A. Warrack, "Valuation of Dynamic Reactive Power Support Services for Transmission Access", IEEE Transactions on Power Systems, Vol. 16, No. 4, pp. 719-728, Nov. 2001.

[5] F. C. Schweppe, M. C. Caramanis, and et al, Spot Pricing of Electricity. Kluwer Academic Publishers, 1997.

[6] M. L. Baughman and S. N. Siddiqi, "Real Time Pricing of Reactive Power: Theory and Case Study Results", IEEE Transactions on Power Systems, Vol. 6, No. 1, 1991.

[7] A. A. El-Keib and X. Ma, "Calculating Short-run Marginal Costs of Active and Reactive Power Production", IEEE Transactions on Power Systems, Vol. 12, No. 2, pp. 559-565, 1997.

[8] V. L. Paucar and M. J. Rider. "Reactive Power Pricing in Deregulated Electrical Markets Using a Methodology Based on the Theory of Marginal Costs", in Large Engineering Systems Conference on Power Engineering, 2001

[9] Y. Dai a, X.D. Liu and Y. X. Ni, "A cost allocation method for reactive power service based on power flow tracing", Electric Power Systems Research, Vol. 64, pp. 59-65, 2003.

[10] G. M. Huang, H. Zhang, "Pricing of Generators Reactive Power Delivery And Voltage Control in The Unbundled Environment", IEEE Transactions on Power Systems, Vol. 13, No. 4, pp. 1226-1231, 1998.

[11] J. B. Gil, T. G. San Roman, and et al, "Reactive Power Pricing: A Conceptual Framework for Remuneration and Charging Procedures", IEEE Transactions on Power Systems, Vol. 15 No. 2, pp. 483-489, 2000.

[12] K. Bhattacharya, J. Zhong, "Reactive Power as an Ancillary Service". IEEE Transactions on Power Systems, Vol. 16, No. 2, pp. 294-300, 2001.

[13] J. Zhong, K. Bhattacharya. "Toward a Competitive Market for Reactive Power", IEEE Transactions on Power Systems, Vol. 17, No. 4, pp. 1206-1215, 2002.

[14] J. Zhong, E. Nobile, A. Bose, and K. Bhattacharya, "Localized Reactive Power Markets Using the Concept of Voltage Control Areas", IEEE Transactions on Power Systems, Vol. 19, No. 3, pp. 1555-1561, 2004.

\section{BIOGRAPHIES}

Dapu Zhao received his B. Sc degree in electrical engineering from Tsinghua University, Beijing, China, in 2000. He is currently a Ph. D candidate in the Department of Electrical Enginerring, Tsinghua University. His research interest is the ancillary services in power market.

Yixin Ni (SM'94) received her B. Eng., M. Eng., and Dr. Eng. fi-om Electrical Engineering Department, Tsinghua University, P.R. China in 1968, 1981, and 1983 respectively. Her research interests are in power system analysis, stability, control, power electronics applications, and power markets. She was a Professor at Tsinghua University and is now with the University of Hong Kong.

Jin Zhong (S'03) received the B.Sc. (Eng.) degree from Tsinghua University, Beijing, China, in 1995 and the M.Sc. (Eng.) degree from the Electric Power Research Institute, Beijing, in 1998, and the Ph.D. degree from Chalmers University of Technology, Gothenburg, Sweden, in 2003.

She worked as a Researcher at the Electric Power Research Institute, Beijing, during 1998-1999. In 2002, she spent five months as a Visiting Scholar at Washington State University, Pullman. Currently, she is an Assistant Professor in the Department of Electrical and Electronic Engineering at the University of Hong Kong. Her areas of interest are electricity sector deregulation and ancillary service pricing. 